\title{
Structural interpretation from Televiewer surveys
}

\author{
RDH Thomas Coffey International Ltd, Australia \\ JM Neilsen Coffey International Ltd, Australia \\ HF Wilson Coffey International Ltd, Australia \\ P Lamb Coffey International Ltd, Australia
}

\begin{abstract}
Structural data collection from drill core relies on the ability of the core to be accurately oriented. A number of methods are available for core orientation, but broken zones and core loss present difficulties in obtaining orientation data, which can result in a paucity of structural data for significant intervals of a drill hole. Where orientation is achieved, errors and uncertainties can result in significant scatter in the calculated structure orientation populations.

Televiewer surveys, both optical and acoustic, provide a reliable and accurate alternative method of recording structural data. They are relatively quick to run, and allow data capture from vertical and inclined drill holes without the need for diamond coring. The Televiewer survey captures a downhole image of the internal drill hole walls. Structural data can be captured from the image by fitting sinusoids to discontinuity traces visible in the drill hole wall. Although structural data can be picked automatically, it is argued that data should be picked by experienced engineers who clearly understand the intended use of the resultant datasets, and the limitations of the surveys. In lieu of a procedure for the undertaking of Televiewer interpretation for structural orientation data for geotechnical purposes, the authors propose a set of guidelines and protocols that in their experience have proven useful.
\end{abstract}

\section{Introduction}

Discontinuities within the rock mass act as planes of weakness along which instability can occur. Part of the geotechnical investigation process involves characterising the minor and major structures within the rock mass, including the nature of the structures and their orientation. The nature of the structures, in terms of their roughness, infill, and wall strength characteristics, are best undertaken through the hands-on assessment of the structures, be that in drill core or exposure. Orientation data can be measured directly from exposure, or indirectly from oriented drill core.

At the design stage, structures are generally characterised from drill core, but broken zones and core loss can present difficulties in obtaining orientation data. This can result in a paucity of structural data for significant intervals of a drill hole. Where orientation of drill core is achieved, errors and uncertainties can result in significant scatter in recorded data.

Televiewer surveys, both optical and acoustic, provide a reliable and accurate method of recording structural data, by capturing a downhole image of the internal drill hole walls, as well as orientation data. They are relatively quick to run, and allow data capture from vertical and inclined holes without the need for costly diamond coring. Structural data can be captured from the image by fitting sinusoids to discontinuity traces visible in the drill hole wall, a process known as 'picking'.

Picking of structural data from Televiewer surveys can be time consuming, but, if undertaken in a systematic manner, it often provides more valuable data than automatically picked data. A number of case studies are presented in order to demonstrate potential issues with manually and automatically picked data and demonstrate the value of having Televiewer interpretation undertaken by experienced engineers. Although standard procedures exist for most forms of geotechnical data collection, the authors are not 
aware of any documentation seeking to standardise the interpretation of Televiewer surveys, and conclude with some guidance on best practice that practitioners may find useful.

\section{$2 \quad$ Collecting structural orientation data from drill core}

\section{$2.1 \quad$ Introduction}

Traditionally, the only method to obtain structural data from drill holes has been via the logging of oriented drill core. Multiple instruments are available to orient drill core; however, the development and availability of Televiewer technologies has provided new methodologies for collecting structural data.

\subsection{Core orientation}

Structural data collection from drill core relies on the ability of the core to be accurately oriented with respect to the drill hole, and the drill hole to be surveyed. Orientation of the core can be achieved by physical marking of the core, or the use of a digital instrument (Davis \& Cowan 2012). Physical marking techniques typically use gravity or an impressionable surface to determine the bottom or low side of an angled hole. Although relatively cheap, physical marking is not suited to vertical or shallow drill holes or where the ground is broken. The mechanisms may fail to activate.

Digital marking techniques are capable of core orientation in angled and only recently, vertical drill holes. The tool is attached directly to the barrel assembly and uses the time stamping of data from multiple accelerometers to record the low side of the core during the drilling process. When the drill run is complete and returned to the surface, the user enters the time into the instrument when the drill run was completed and drilling had ceased, just prior to breaking the core. The position of the instrument could then be recovered, enabling the instrument to guide the user to mark the low side of the core. Although more expensive; digital marking techniques are more accurate and reliable than physical methods. One orientation mark is attempted per drill run. In competent ground, it is possible to join/lock stubs of core together to transfer and validate the orientation marks from consecutive runs. The more consecutive orientation marks that can be joined increases confidence in the reliability in the position of a 'bottom-of-core' reference line. This reference line is marked on the drill core and used in geotechnical logging as the reference to record orientation data for each structure. Where a broken zone is encountered, or core has spun in the barrel, or it is not possible to join stubs of core together confidently, the orientation line cannot be continued, resulting in a loss of oriented structural data.

Broken zones can significantly impact the effectiveness and accuracy of both physical and digital techniques. For weak rock masses, or those where defects are well developed (bedded strata for example), it can be common for the drilling process to disturb the core, resulting in both loss of the orientation mark, and any structures where other defect characteristics could have been recorded. These issues can result in a paucity of structural data for significant portions of the drill hole or even the entire project. If an alternative source of structural data is not available, gaps in the model can result in greater uncertainties and requirement for conservatism in design.

\subsection{Measurement of structural data}

The orientation of individual structures can be determined from drill core by measuring the alpha and beta angles during drill core logging, as outlined by ISRM Commission on Standardisation of Laboratory and Field Tests (1978) and presented below in Figure 1. The alpha angle is the maximum angle of intersection between the discontinuity surface and the core axis. The beta angle is measured around the circumference of the core from the orientation line to the maximum down-hole apex of the discontinuity. The accuracy of these measurements is determined by the skill of the logger and quality of the core recovered. These angles are then converted to a true dip and dip direction by using the downhole survey. Intervals over which this survey is undertaken can vary based on the instrument used, and can range from millimetres to 10 s of metres. The more frequent the survey, the more accurate the orientation will be. 

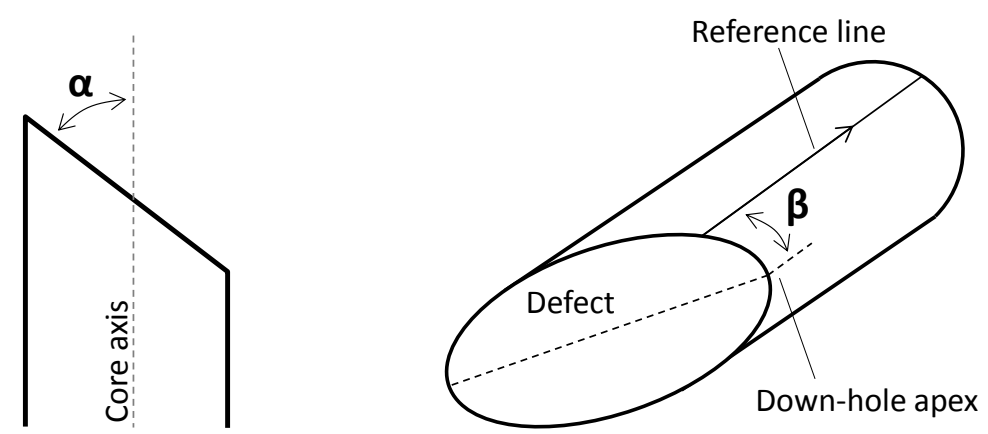

\section{Figure 1 Measurements of discontinuity orientation from drill core (after Barrett, Fuller \& Partners 2001)}

As an alternative to manual measurement of the alpha and beta angles, these can be extracted from digital photography using software such as StereoCore PhotoLog (Orpen 2007). The system has specific requirements for the core photography, and creates a 3D model of the core within the core tray. Given the requirement to obtain physical characteristics from the core and each defect during logging, the author's preference is for physical measurement of the alpha and beta angles.

\subsection{Limitations \& accuracy}

Obtaining structural data in this manner requires the relatively expensive drilling of diamond core, and a high level of supervision may be required to ensure confidence in orientation and core marking procedures. Errors in orientation can occur at several stages in the process and the driller's technique and understanding of the tool being used is crucial, as discussed by Davis and Cowan (2012). Sensibility checks to ensure the orientation mark is translated correctly are required. Where the orientation line is continued over defects, the stubs of core must lock together precisely.

The existence of broken zones and core loss present difficulties in obtaining orientation data, which can result in a paucity of structural data for significant intervals of a drill hole. Where core orientation is achieved, errors and uncertainties are estimated to be between $9^{\circ}$ and $16^{\circ}$ at best (Holcombe 2013), resulting in significant scatter in recorded data. Additional errors can also occur through the imprecise nature of alpha and beta measurement techniques during logging.

\section{$3 \quad$ Televiewer surveys}

\subsection{Introduction}

Televiewer data, both optical and acoustic, is becoming more frequently recorded along with geophysical downhole surveys, and provides a reliable and accurate method of recording structural data. The Televiewer survey captures a downhole image of the internal drill hole walls. Two types of Televiewer surveys are used - optical, which uses lights and a camera to provide a direct image of the drill hole wall, and acoustic, which uses the amplitude of a reflected acoustic signal.

\subsection{Survey considerations}

Televiewer surveys can be used as a cost effective data collection tool; however, certain considerations should be noted to achieve effective surveys. Existing open drill holes can be surveyed subsequent to the drilling programme if they remain open. The cleanliness of the drill hole wall is critical to the quality of the survey, and cleaning, or flushing of the hole may be required. The probes are expensive and where there are indications of potential instabilities, such as highly fractured zones, the risk of hole collapse and the potential loss of the probe should be considered. Casing through near surface materials may be required to provide drill hole stability for the survey. Where this applies, it is generally preferable to undertake the survey during the drilling programme to allow subsequent casing retrieval by the drill contractor. 
Acoustic Televiewer (ATV) surveys must be carried out in fluid (i.e. water) filled drill holes. A dry or partially filled drill hole can be filled to achieve this; however, gas bubbles will inhibit the value of the survey (Gwynn et al. 2013). Optical Televiewer (OTV) surveys, although predominantly used above the water table, may also be undertaken in water filled drill holes. The water must be clear of mud and debris, as only small amounts of suspended sediments can significantly cloud the resultant image. Generally, OTV is preferred above the drill hole water level, and ATV below. Both survey types may be used on a single drill hole to provide a complementary dataset.

OTV surveys can be undertaken in dry or partially filled drill holes. It is recommended that the drill holes be washed to remove mud on the drill hole walls prior to the survey to provide a clean image for interpretation.

The drilling method used can affect the character of the drill hole wall and resultant quality of the Televiewer image. Diamond coring tends to produce the smoothest drill hole wall, and reverse circulation drilling tends to result in a less uniform hole, with greater potential for disturbance of soft or broken zones.

The Televiewer probe records downhole survey data, recorded using an array of magnetometers and accelerometers. Where magnetically susceptible units are being surveyed, magnetometer based surveys should be checked against surveys undertaken using gyroscopic methods.

\subsection{Interpretation of structural data}

The Televiewer image is generally presented for interpretation as an unrolled cylinder using software such as WellCAD. Logged geological, geotechnical and geophysical data can also be presented alongside the 2D representation of the survey, greatly aiding interpretation. An example is presented in Figure 2.

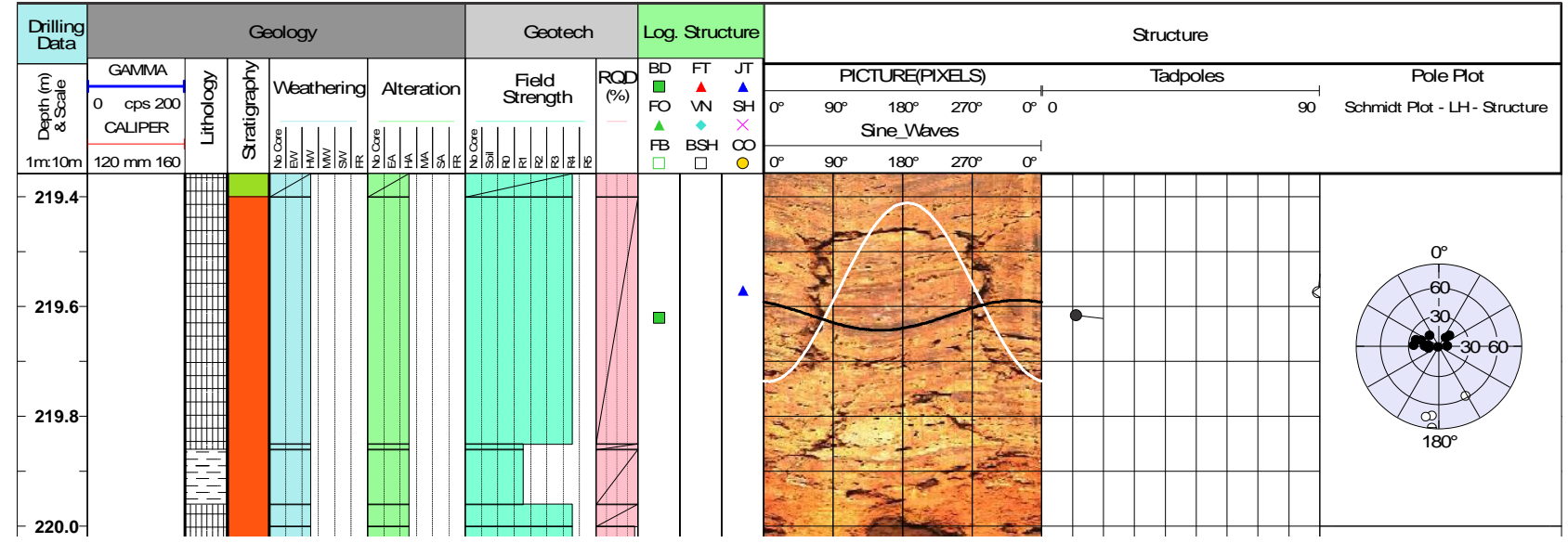

\section{Figure 2 Example log for OTV data with incorporated geological and geotechnical data}

Prior to undertaking any Televiewer interpretations, consideration is given as to the nature and composition of the rock mass that is shown in the downhole image. Considerations such as lithology may impact the colour contrast in the optical image and therefore the quality of interpretations possible. The dominant structure type or fabric anticipated within the rock mass is useful knowledge for an interpreter prior to beginning the interpretation. At a most basic level, a considered evaluation of the image in its entirety is recommended to familiarise the interpreter with the overall structural setting, and allow evaluation of the quality of the survey image.

Structural data is captured from the image by fitting sinusoids to images of interpreted discontinuity traces visible in the drill hole wall. The Televiewer probe records downhole survey data to accuracies of $\pm 0.2^{\circ}$ dip and $\pm 1.0^{\circ}$ azimuth. Each picked sinusoid is resolved using the survey data to provide a true dip and dip direction for each structure.

Televiewer interpretation is not simply a case of fitting traces over sinusoids present on the image. In order to correctly classify the structures, some level of interpretation is required. Trice (1999) provided some 
guidance on the judgements made by the engineer/geologist interpreting such traces. He provided guidance on a two-step process of first classifying sine waves picked from a drill hole, and secondly assigning a geological classification, presented in a modified form in Figure 3. Although these steps may be undertaken subconsciously by an experienced operator, their provision is a useful aid for uncertain scenarios. Identifying whether a trace is transmissive (a poor responder to the sensing medium) for instance, may indicate a partially washed out shale band within a more competent lithology. Correctly identifying and classifying sine waves is critical to the integrity of the structural dataset on which geotechnical assessment will be undertaken.

\section{SINE WAVE ANGULAR ATTITUDE}

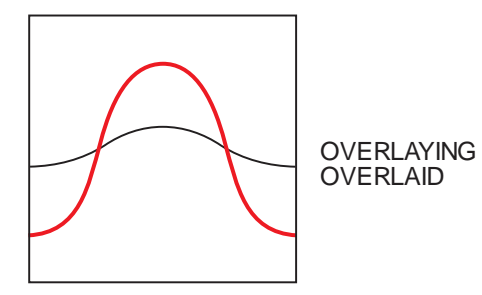

SINE WAVE FABRIC ATTITUDE

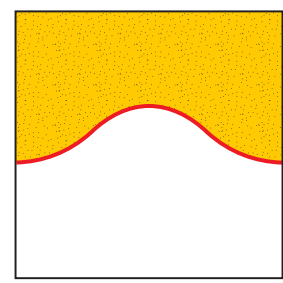

INTERFACE

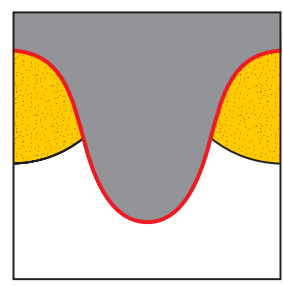

DISPLACIVE

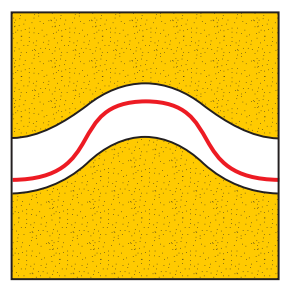

FABRIC BOUND

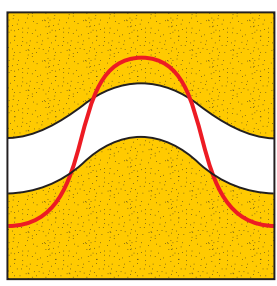

FABRIC CUTTING

TRANSMISSIVE-REFLECTIVE

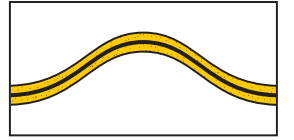

TRANSMISSIVE

\section{APPARENT TRACE LENGTH CONTINUITY}

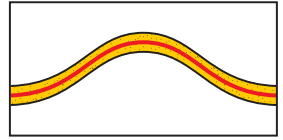

CONTINUOUS

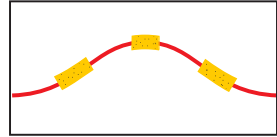

DISCONTINUOUS

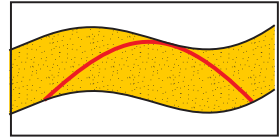

PARTIAL

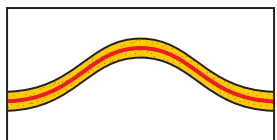

REFLECTIVE

COMMON GEOLOGICAL FORMS

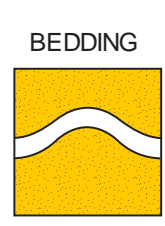

INTERFACE
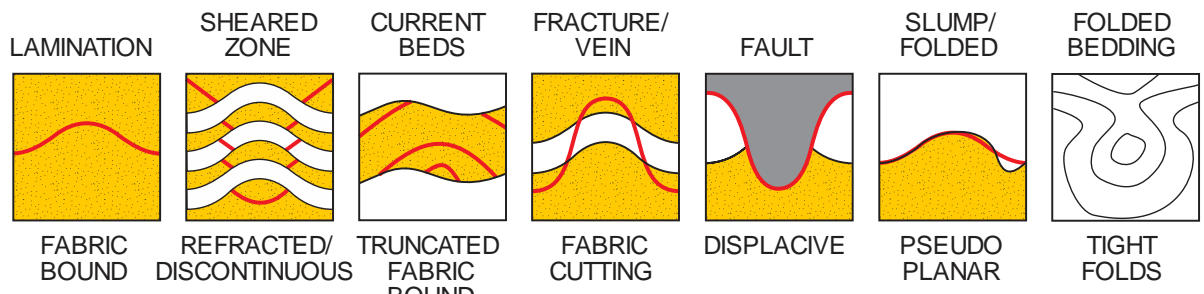

Figure 3 Sine wave classifications and example geological forms (after Trice 1999) 


\subsection{Limitations}

Whilst Televiewer surveys of defects are constrained by the same orientation bias as oriented drill core logging, they can be undertaken irrespective of the dip of the drill hole and allow augmentation of structural databases by logging of reverse circulation drill holes.

The Terzaghi correction (Terzaghi 1965) can be applied to Televiewer data as with traditional drill core structural data sets to provide an understanding of drill hole orientation bias. As the correction requires a set spacing along a continuous drill hole traverse, a simplification of Televiewer downhole survey is likely required. It should be noted that for the correction to be effectively applied, data points must exist in the under-sampled orientations windows.

Televiewer surveys, whilst providing valuable and cost effective digital data, cannot replace the critical physical samples provided by traditional core logging. The wealth of structural data that can be recorded from the surveys must be qualified by core logging of the surface profiles and small scale roughness of relevant indicative samples from each structure set and type. Laboratory and field test work on drill core samples are imperative to rock mass characterisation and so adequate drill core will always be required as part of the geotechnical data collection process.

The main limitation of the ability to collect structural data from Televiewer surveys is the cleanliness of the interior drill hole wall. This can be controlled through the use of purpose made washing units prior to surveying but this is not routine.

It should also be noted that Televiewer data is collected from images of the intact/confined drill hole walls and core logs are made from examining the unconfined core following drilling and handling practices. Depending on the depth and stress conditions of the investigation location, drill core may better represent a rock mass exposed in the walls of an open pit which has had some disturbance or stress relief. Televiewer data reflects an in situ rock mass which is confined, and yet to be disturbed by excavation. This is one reason why the authors recommend the use of Televiewer as a tool for collecting orientation data rather than replacing core logging for assessing other parameters such as rock-quality designation (RQD) and fracture spacing.

\subsection{Accuracy}

Gwynn et al. (2013) estimate that the errors associated with structural data derived from Televiewer picks for the azimuth angle are in the order of $5^{\circ}$. The authors have tested the reliability of Televiewer measurements using several experienced engineers' interpretation of the same Televiewer image, following the guidelines provided above. The comparison between the resulting structural logs resulted in differences of up to $3^{\circ}$ in the dip and $6^{\circ}$ in the dip direction of individual structures, translating to uncertainties of $\pm 1.5^{\circ}$ and $\pm 3^{\circ}$ dip and dip direction respectively. Incorporating the limitations of the drill hole survey method results in maximum potential errors of $\pm 1.7^{\circ}$ and $\pm 4^{\circ}$ dip direction when drill holes are drilled approximately normal to bedding planes. This is summarised in Table 1 . The reduced uncertainty achieved relative to that quoted by Gwynn et al. (2013) is attributed to the detailed guidelines developed by the authors in an attempt to ensure consistency between users.

Table 1 Interpreted uncertainty in orientation of structural picks from Televiewer survey

\begin{tabular}{c|cc}
\hline Source of uncertainty & Dip & Dip direction/azimuth \\
\hline Downhole survey & $\pm 0.2^{\circ}$ & $\pm 1.0^{\circ}$ \\
Structural picks & $\pm 1.5^{\circ}$ & $\pm 3.0^{\circ}$ \\
Cumulative uncertainty & $\pm 1.7^{\circ}$ & $\pm 4.0^{\circ}$ \\
\hline
\end{tabular}


Televiewer interpretation provides a more accurate and reliable method of obtaining structural data from drill holes over traditional logging of oriented drill core. Structural bedding data, derived from core logging and Televiewer interpretation from a drill hole in banded iron formation, are presented in Figure 4. The two stereonets shown display the (a) drill core measured structures and (b) Televiewer interpreted structures. The larger scatter in the drill core dataset is attributed to the increased errors associated with logging structures from drill core. The drill core dataset is a significantly smaller population than that from Televiewer interpretation. This is attributed to the ability to interpret fully oriented structure over the full length of the Televiewer image, in comparison to drill core in which it can be difficult to maintain a consistent orientation reference line over the length of the drill hole.

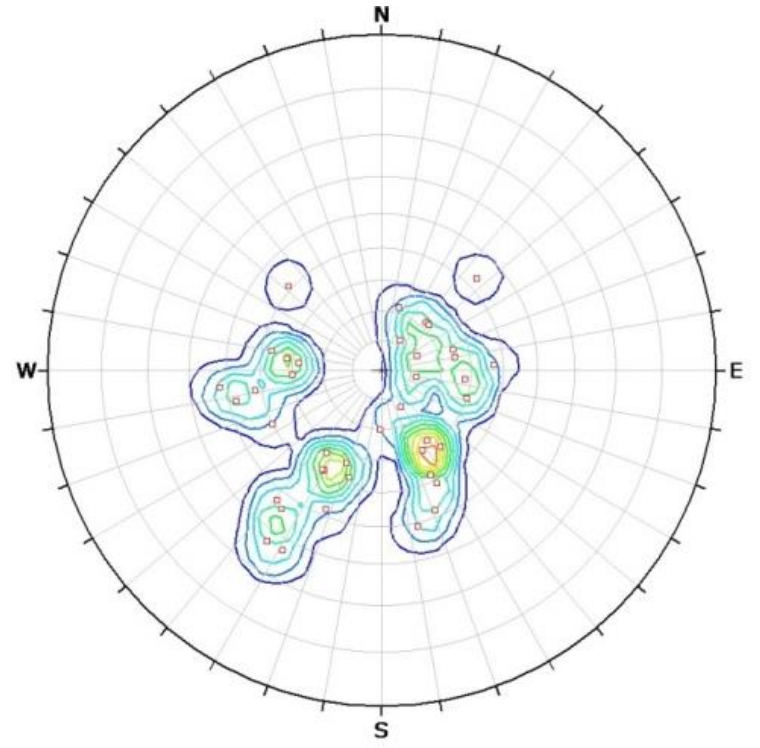

(a)

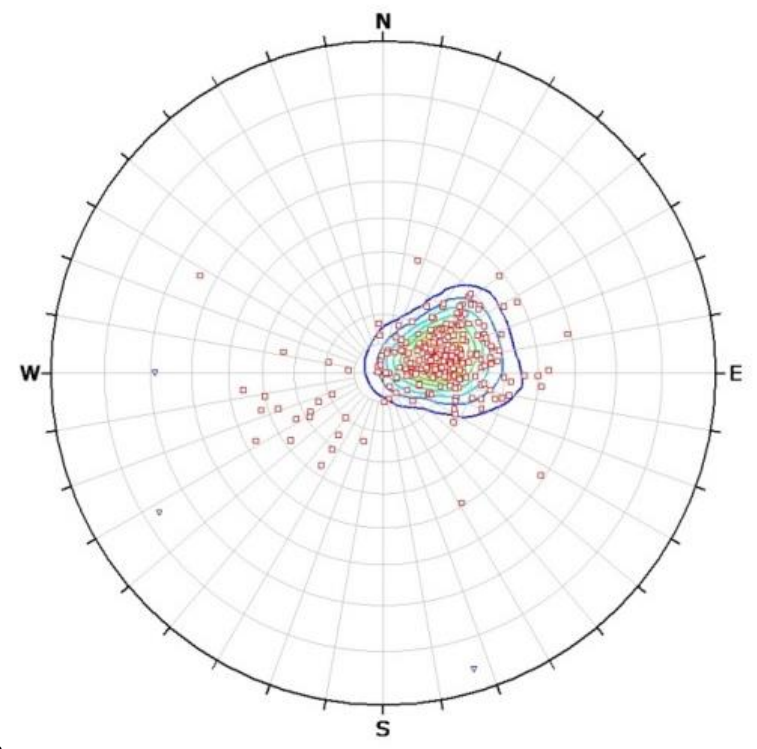

(b)

\section{Figure 4 Structural orientations from drill hole A from (a) drill core data, $\mathbf{N}=\mathbf{4 4}$ (b) Televiewer, $\mathbf{N}=243$}

\section{$4 \quad$ Considerations for data collection from Televiewer surveys}

Optical and acoustic Televiewers provide a method of obtaining structural data from drill holes with significant advantages over traditional data collection techniques. Unlike logging core, however, guidelines are not available to ensure best practice is followed. The following sections highlight some items from the authors' experience that have led to issues with use of data from Televiewer survey.

\subsection{Planning structural data collection}

The intended use of the structural data should be considered prior to design of the drilling/Televiewer programme in order to ensure data is targeted and bias accounted for. A logical project nomenclature should be adopted for planning, data collection purposes, and be maintained through the data collection process.

Sensibility checks on the acquired dataset, such as downhole survey and caliper values should be undertaken to ensure the survey grid used is appropriate and that the correct caliper value is used for processing of interpreted structures. Issues can arise during creation of files for data picking from the raw survey files. The convention of the alignment of north should be checked for each probe used for each project, as these can vary. It is also useful to note at this stage any observed data quality issues, which, if they cannot be rectified, may bias the survey.

Similarly, the resolution of the required dataset should be considered prior to data collection from drill core or Televiewer in order to provide the most appropriate dataset given available resources. For example, an individual drill hole may be processed to aid in the production of geological models, requiring a focus on 
collecting data on the location and orientation of large scale structures and geological contacts. Recording structural orientation data for all structures may cloud the selection of these critical structures, and significantly extend the timeframe. Similarly if a drill hole extends through a unit where many healed structures and veinlets are present, these may be inconsequential for kinematic geotechnical analysis. In such a case, the data collection may be better focused on open structures (joints and faults) plus any other significant features.

If the structural interpretation is to be used to characterise a dominant structure, such as bedding, across a deposit, a large and consistent dataset is required. The instruction may be to collect all secondary defects (joints, faults, etc.), all open bedding planes and traces of bedding at nominated downhole intervals in order to sample without bias. Interpreting structures at regular downhole intervals is likely to be of greater importance than maximising the total number of structures surveyed. Where trends are not immediately apparent through observation of a stereonet or using 3D visualisation software, assessment may also be made by viewing the apparent dip in the plane of interest (i.e. a section orthogonal to a pit slope), as shown in Figure 5. Resolving the data in this format allows easy identification of the minimum, maximum and average apparent Televiewer dip, as well as how the apparent dip varies downhole. In this format, it is also easy to compare the average apparent dip of the Televiewer data with the dip of the bedding in the structural model as a method of model validation. In this example, the apparent dip of the structural model was noted to be steeper than the average apparent bedding dip by approximately $7^{\circ}$ over the interval. 

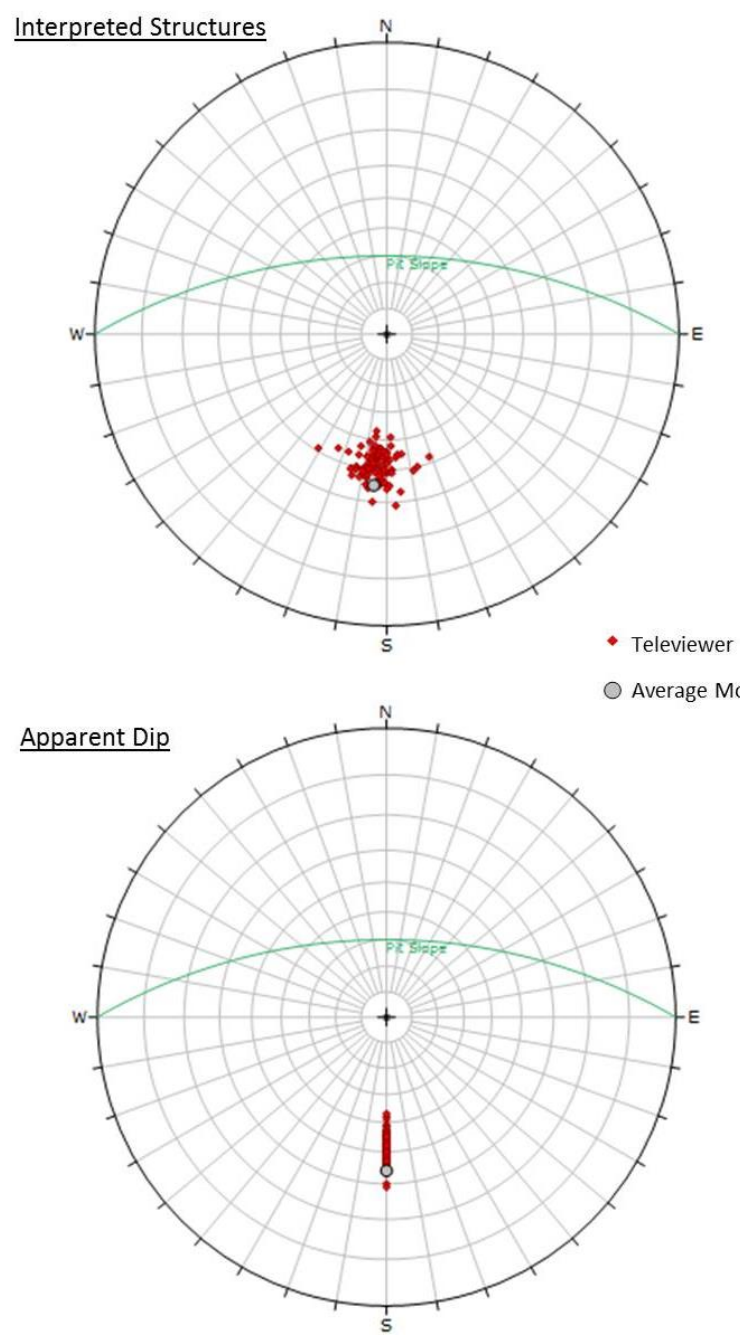

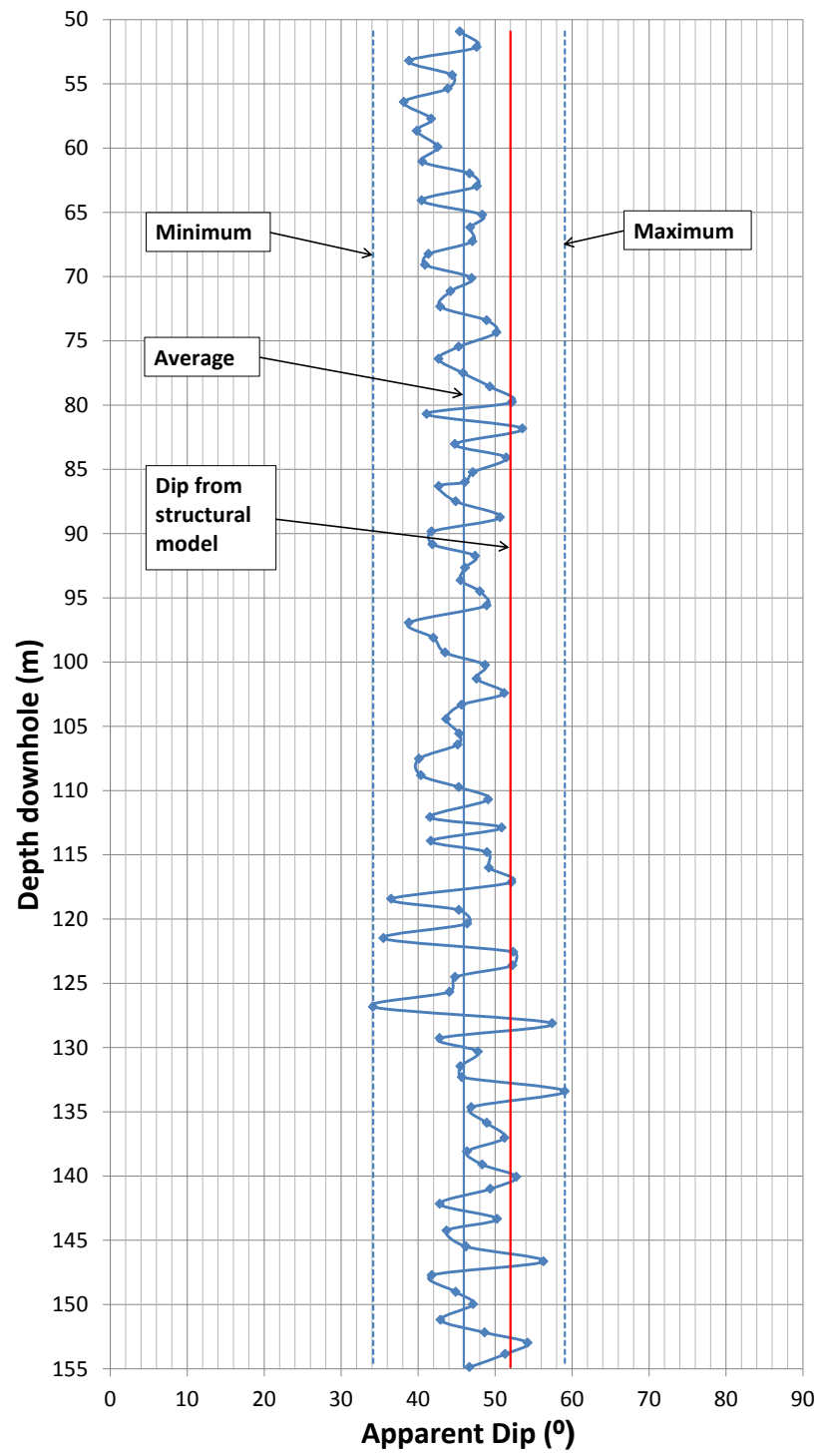

Figure 5 (a) Stereographic plots of Televiewer derived bedding orientation data from a $100 \mathrm{~m}$ interval of consistent modelled bedding dip, and resolved as apparent dips in the plane of interest; (b) downhole plot for $105 \mathrm{~m}$ of Televiewer bedding data as apparent dips in the plane of interest

\subsection{Imperfect structures}

As with logging of drill core, structures that intersect the drill hole trace at high angles are the simplest to accurately measure for orientation. For structures that have non-planar profiles (i.e. exhibit roughness at the drill hole scale) the authors recommend the practitioner adopts a methodology that ensures structural data is recorded consistently. The authors have previously elected to prioritise the 'fit' of the sinusoid in the following order:

- The downhole 'peak' of the structure sinusoid.

- The upper 'peak' of the structure sinusoid (prioritising downhole depth over location in x-axis of Televiewer image).

- The adjustment for best fit for the remainder of the sinusoid.

These points are directly related to the alpha and beta angles recorded from core, with the distance across the Televiewer image from the survey reference corresponding with the beta angle and the amplitude of the sinusoid corresponding to the alpha angle. This is illustrated in Figure 6. 


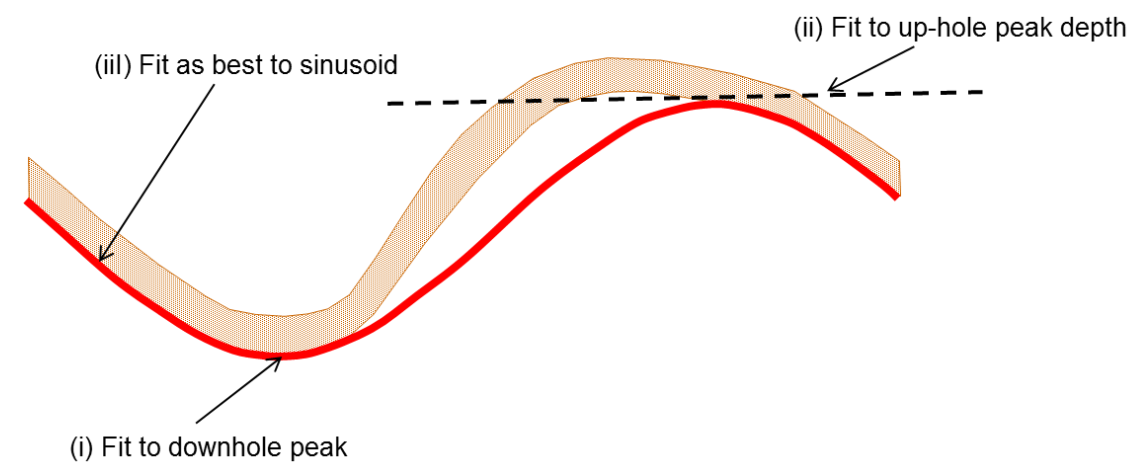

Figure 6 Methodology for fitting sine wave to non-planar structure

A standardised 'sinusoid fit' process such as that outlined above will allow the practitioner to collate a consistent dataset, regardless of the orientation of structures or degree of deformation within different rock masses.

These recommendations for a 'fitting' methodology assume that a full sine wave is legible in the image. This is not always the case in Televiewer surveys. Continuous structures are the simplest form to fit accurate sine waves; however, non-continuous or partial structures may be present due to displacement by another structure set, or due to poor formation of the structure or fabric. Such structures may represent discontinuous shear zones or features that refract across materials of varying competency. For a non-continuous structure, the authors recommend that at a minimum, at least one inflection point of the structure must be visible for an accurate interpretation (Figure 7). Where the structure is discontinuous or truncated, this should be noted as a property of the interpretation, both for an assessment of the reliability of the structural orientation and as a measure of the persistence of the structure.

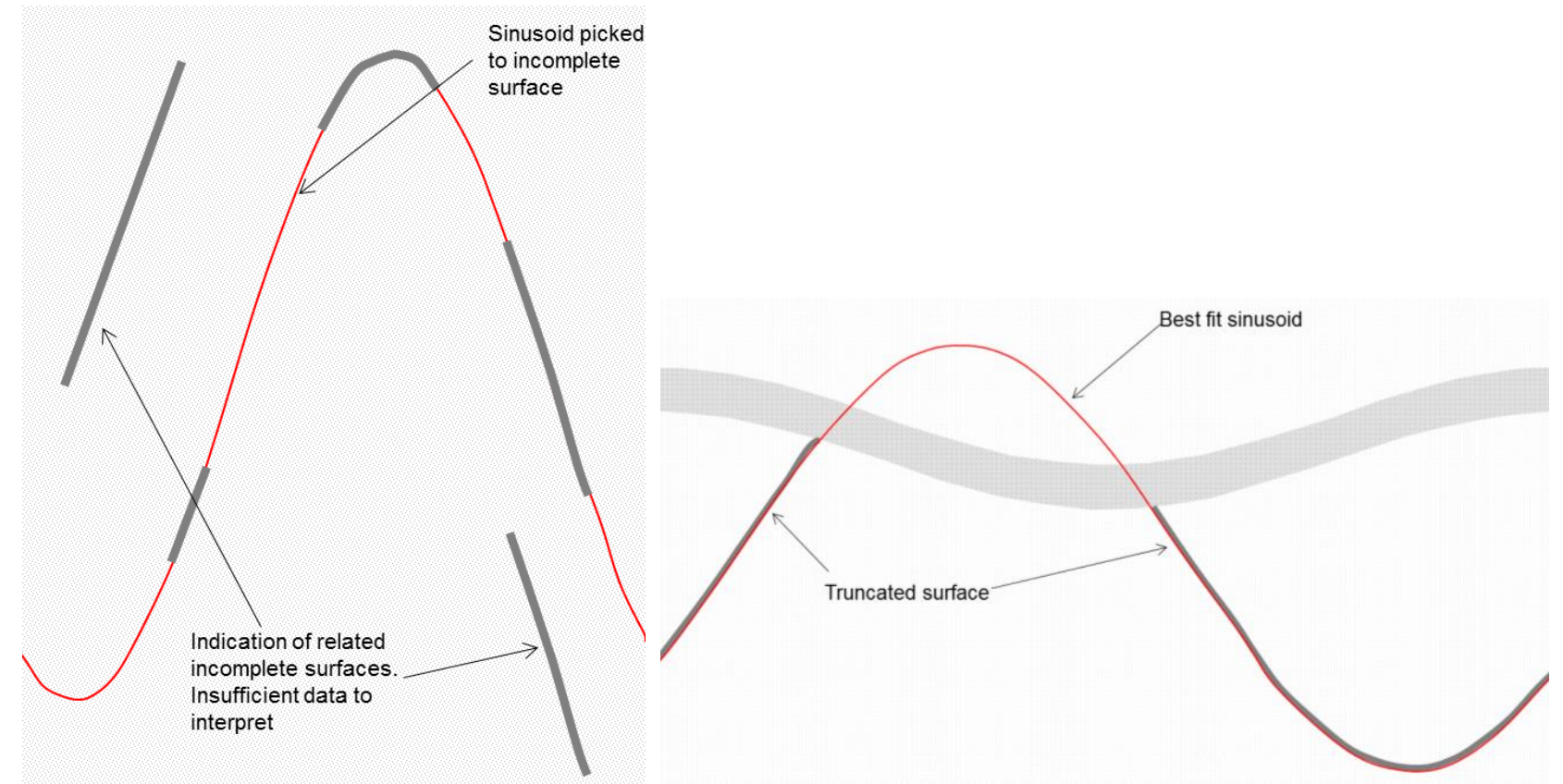

Figure 7 (a) Sine wave interpreted on incomplete surface; (b) Sine wave interpreted on incomplete surface

\subsection{Image quality}

A further consideration to the reliability of the structural interpretations is the quality of the image, which can vary dramatically downhole. Factors such as the cleanliness of the drill hole wall, changing strata competency or different drilling techniques, water in an OTV survey, or the presence of gas bubbles in an 
ATV survey can all result in poor quality images. Drill hole wall cleaning units, which remove drilling muds and cuttings from the drill hole wall prior to surveying, are available and should be considered. The reliability of each structural interpretation should be recorded for data validation purposes. A record should be maintained during the interpretation process of the quality of each survey and the potential effect of any issues on the resultant database.

\subsection{Issues with automated picking}

Automated picking of structures can result in rapid fitting of a large number of sinusoids to data from Televiewer surveys. This can provide interpretation at reduced cost, but can lead to issues with the data in terms of the assignment of structure types and clouding of data. Significant time can be required in data review and filtering to obtain a useful dataset, as would have been required in the example shown in Figure 8 (above clouding issue). Automatic interpretation can also lead to the erroneous identification of structural features normal to the drill hole (i.e. horizontal on the 2D trace) caused by the drilling process. Figure 8 below shows an example where three such features were assigned over a $1.5 \mathrm{~m}$ downhole depth. Each was resolved to have exactly the same orientation.
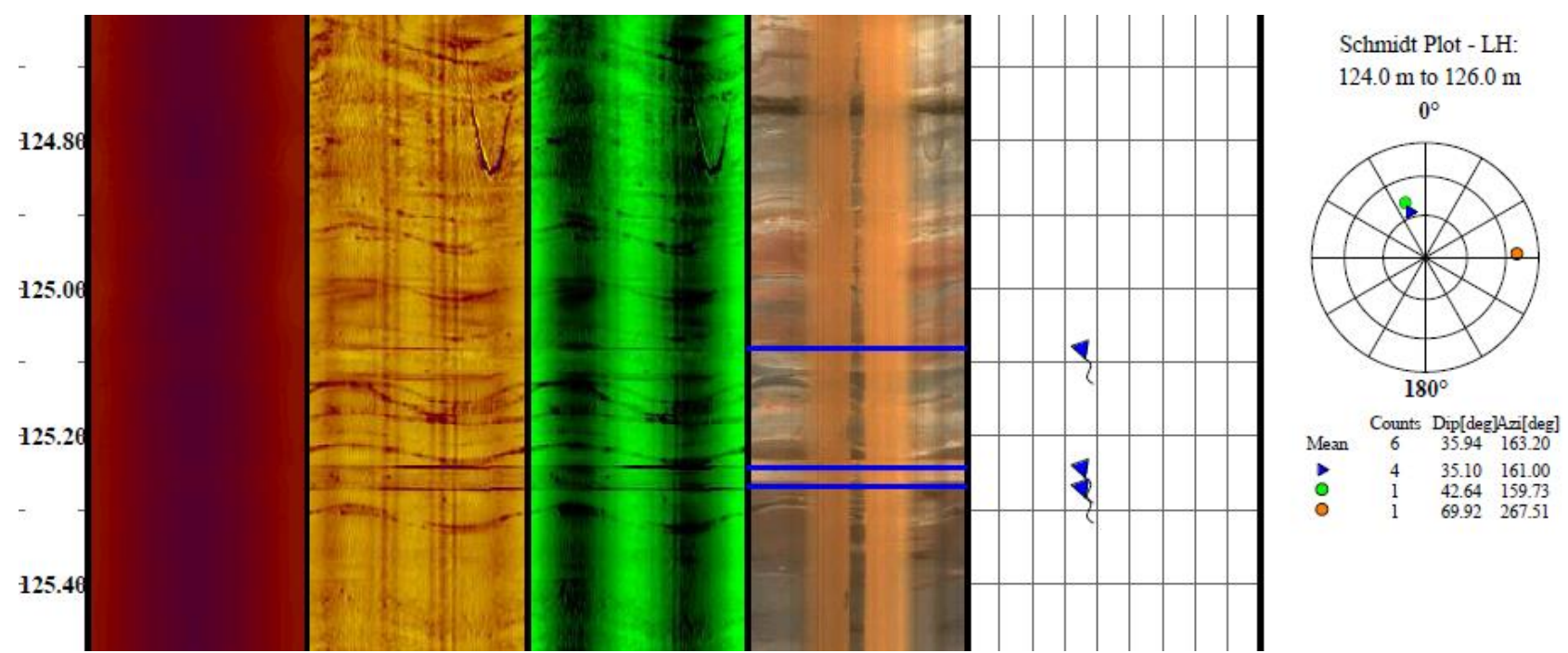

Figure 8 Automatically picked sinusoids resulting in misinterpretation of structure

\subsection{Consistency of personnel}

Although manual picking of orientation data from Televiewer data is preferred, it is not without its issues. Consistency between different personnel, and even of a single engineering geologist working over a protracted period, must be ensured. The authors have found that a defined set of guidelines for a project based on the aims of the data collection programme greatly assists with ensuring this consistency. As with geotechnical logging of drillcore, ensuring timely review of structural logging takes place and providing resultant feedback can greatly assist in this regard. Figure 9 shows interpreted Televiewer logs of the same geological unit for the same project delivered by the same contractor at separate times. Figure 9(a) shows significantly greater resolution of picking than Figure $9(b)$. This data was to be compared to validate logged RQD and fracture frequency, and when the data was filtered by the individual that undertook the logging, it was clear that the datasets collected by each contained significant differences.

\section{$5 \quad$ Conclusion and considerations}

Structural data collected from Televiewer surveys resolves many issues associated with structural orientation data collection from drill core, and provides data of a higher accuracy. It does not, however, replace drill core logging as it cannot provide the same level of data on defect and defect wall characteristics as physical assessment by an experienced engineering geologist. Televiewer data is collected 
from images of the intact/confined drill hole walls and reflects an in situ rock mass yet to be disturbed by excavation.

Many of the orientation biases associated with collecting 3D data from a drill hole still exist with Televiewer data. A Terzaghi correction can be used to provide a better understanding of drill hole orientation bias.

Undertaking structural picks from Televiewer surveys can be time consuming. Software is available for the automated picking of structures although this software can lead to a number of issues. In the authors' opinion, manual interpretation by an experienced engineer/geologist provides a superior outcome in most cases. If automated picking is used data should be thoroughly reviewed prior to use.
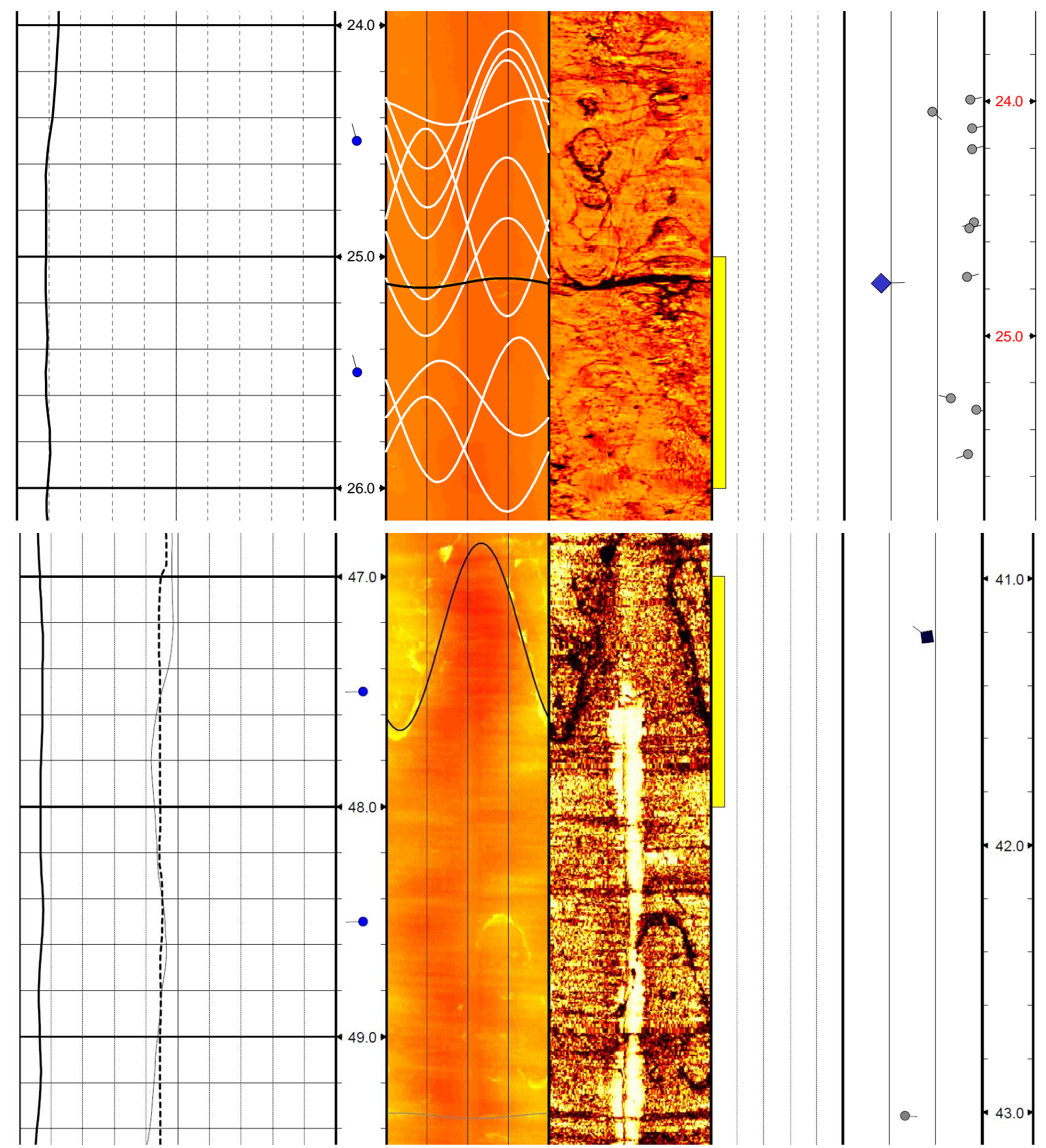

Figure 9 (a) Interpreted Televiewer data from Batch A; (b) Interpreted Televiewer data reported subsequently to (a). Additional joints and foliation traces could have been identified 
In order to maximise the value and use of the data collected from Televiewer surveys, it is necessary to plan the data collection programme appropriately and tailor the interpretation to the proposed use of the data. In lieu of a procedure for collecting structural orientation data from Televiewer surveys, the authors offer the following points that practitioners may find useful when planning and undertaking data collection using Televiewer surveys:

- File creation from software into picking software - be aware of potential issues relating to Magnetic north (i.e. different probes having different grid norths).

- Import of additional data where available - sensibility check on survey data, caliper and all others.

- Record data on the quality of survey in an easily accessible file to make it clear where survey quality has affected the database.

- Use an agreed project nomenclature and defined structure types.

- Define a methodology for the project which sets out the degree of resolution and structural pick requirements.

- Reference available geological, geotechnical logs and drill core photos when undertaking interpretation.

- Define methods for fitting 'imperfect' sinusoids, such as prioritising the 'fit' of the sinusoid in the following order:

- The downhole 'peak' of the structure sinusoid.

- The upper 'peak' of the structure sinusoid (prioritising downhole depth over location in $\mathrm{x}$-axis of Televiewer image).

- Then adjust for best fit for the remainder of the sinusoid.

- Set out guidance on the assignment of structure types for assignment of imperfect/unreliable features.

- Assign a level of confidence for each sinusoid picked, allowing for measures of both the confidence of the structure type, and the precision of the fit of the sinusoid.

- Ensure consistency between multiple project personnel involved in Televiewer interpretation.

- Consider exporting alpha and beta data from the program, rather than dip and dip direction. This will allow a Terzaghi correction to be undertaken and provide a check of Televiewer survey alignment.

- Undertake a sensibility check of dominant structural orientations with the structural model of available core logging data.

- A quality review should be undertaken, as it would for geotechnical logging. Feedback should be provided in a timely manner.

\section{Acknowledgement}

The authors would like to thank Joe Cadman for undertaking a critical review of this paper and Coffey for providing the resources to publish this document.

\section{References}

Barrett, Fuller and Partners 2001, Geotechnical core logging manual (unpublished).

Davis, BK \& Cowan, EJ 2012, 'Oriented core - what the...?', in J Vearncombe (ed.), Proceedings of the Structural Geology and Resources - International Symposium Abstract Volume, Australian Institute of Geoscientists, Perth, pp. 61-63. 
Gwynn, XP, Brown XC \& Mohr JP 2013, 'Combined use of traditional core logging and Televiewer imaging for practical geotechnical data collection', in P Dight (ed.), Proceedings of the 2013 International Symposium on Slope Stability in Open Pit Mining and Civil Engineering (Slope Stability 2013), Australian Centre for Geomechanics, Perth, pp. 261-272.

Holcombe, R 2013, Oriented drillcore: measurement, conversion, and QA/QC procedures for structural and exploration geologists, Holcombe, Coughlin and Oliver Consultants, viewed 1 June 2015, http://www.holcombecoughlinoliver.com/ downloads/HCO_oriented_core_procedures.pdf.

ISRM Commission on Standardisation of Laboratory and Field Tests 1978, 'Suggested methods for the quantitative description of discontinuities in rock masses', International Journal of Rock Mechanics and Mining Science, vol. 15, no. 6, pp. 319-368.

Orpen, J 2007, 'Introducing the drillhole surveying benchmarking project - Voorspoed mine', Journal of Institute of Mine Surveyors of South Africa, vol. 32, no. 6, pp. 507-512.

Terzaghi, RD 1965, 'Sources of error in joint surveys', Geotechnique, vol. 15, pp. 287-304.

Trice, R 1999, 'A methodology for applying a non unique, morphological classification to sine wave events picked from drillhole image log data', in MA Lovell, G Williamson \& PK Harvey (eds), Borehole Imaging: applications and case histories, Geological Society, London, Special Publications no. 159, pp. 77-90. 
